\title{
In silico and Molecular Docking Studies of Black Pepper Phyto-constituents against EmrD Efflux Pump of $E$. coli
}

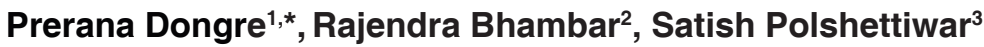 \\ ${ }^{1}$ Symbiosis Institute of Health Sciences, Symbiosis International (Deemed University), Pune, Maharashtra, INDIA. \\ ${ }^{2}$ MGV's Panchavati College of Pharmacy, Nasik, Maharashtra, INDIA. \\ ${ }^{3}$ School of Pharmacy, Dr. Vishwanath Karad, MIT World Peace University, Pune, Maharashtra, INDIA.
}

\begin{abstract}
Multidrug resistance (MDR) bacterial infection is the next pandemic waiting behind the COVID-19 with annual mortality rate 700000 worldwide. Among the MDR bacteria, Escherichia coli, Staphylococcus aureus, Klebsiella pneumoniae, Acinetobacter baumannii, Pseudomonas aeruginosa, Enterococcus faecium and Enterococcus faecalis are showing average resistance of 50 to $80 \%$ to ampicillin, amoxicillin, third-generation cephalosporin's and fluoroquinolone and even to combinations antibiotics such as amoxicillin-clavulanic acid. To make the antibiotic resistance issue worst, pharmaceutical industry is reluctant to invest in research and development of new antibiotic typically due to low returns on investment. Accordingly, use of combination of two or more antibiotics or use of the antibiotic adjuvants are only available ways in combatting the ever growing Multidrug resistance (MDR) in bacteria. The present paper is designed to analyze the synergistic potential of black pepper phyto-constituents as the amoxicillin adjuvants in comparison with isolated piperine against the MDR E. coli. using in-silico molecular docking. The result indicates that binding energy $(\mathrm{Kcal} / \mathrm{mol})$ and torsion free energy $(\mathrm{Kcal} / \mathrm{mol})$ of piperine $(-6.23,+0.89)$, beta caryophyllene $(-6.36,+0.00)$, beta selinene $(-6.93,+0.30)$, beta-Thujene $(-5.42,+0.30)$ is less for the emrD efflux pump as compared to amoxicillin $(-5.85,+2.93)$ respectively indicating strong inhibition for EmrD of MDR E-coli than amoxicillin. The results are also indicating that black pepper extract containing all aforementioned phyto-constituents has synergistic effect in comparison with isolated piperine against the MDR E. coli. ADMET of these phyto-constituents also indicates their safety profile in combination with amoxicillin.
\end{abstract}

Key words: Multidrug resistance (MDR), Piperine, In silico molecular docking, Efflux pump, E. coli, Black pepper, Amoxicillin.

\section{INTRODUCTION}

The resistance to antibiotics is a natural survival manifestation developed by the bacteria to resist the prejudicial effect of the antibiotics. However, anthropogenic influences, such as antibiotic overuse, inappropriate prescriptions, irresponsible agricultural practices of using farm antibiotics to avoid plant diseases, using antibiotics to treat or prevent diseases in animals, further contributes to the emergence of Multi Drug Resistance (MDR) in bacteria. It is evident that, $65 \%$ increase in global antibiotic consumption in humans between 2000 and 2015, 11.5\% increase in use of antibiotics in animals between 2017 and 2030 directing global antibiotic consumption to increase by 200 percent between 2015 and 2030. ${ }^{1,2}$ Further, MDR bacterial infections are estimated to rise to 10 million by 2050 , indicating to surpass cancer morbidity.

According to aforementioned trajectories MDR bacterial infection will be one of the biggest threats to the public health
Submission Date: 04-03-2021; Revision Date: 06-05-2021; Accepted Date: 08-10-2021.

DOI: 10.5530/ijper.56.1.23 Correspondence: Mrs. Prerana Dongre,

Symbiosis Institute of Health Sciences, Symbiosis International (Deemed University), Pune- 412115, Maharashtra, INDIA.

E-mail: ppd.ipr@gmail.com

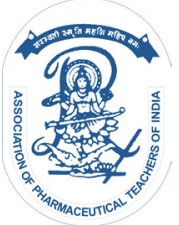

www.ijper.org 
with annual mortality rate 700000 worldwide. Recent reports of WHO indicates that India lead the world in the antibiotic consumption with widespread use of broad-spectrum antibiotics as penicillin's, cephalosporin's and Fluoroquinolones, typically due to its easy accessibility and affordability. To make matters worse, COVID-19 pandemic is paving the way for MDR in bacteria, typically due to increased prescriptions and dispensing of antibiotics, though COVID-19 is caused by SARS-CoV-2 virus and not by bacteria.

Consequently, India support and move the considerable burden of drug-resistant pathogens especially, Escherichia coli, Staphylococcus aureus, Klebsiella pneumoniae, Acinetobacter baumannii, Pseudomonas aeruginosa, Enterococcus faecium and Enterococcus faecalis. ${ }^{1}$ As per the Resistance map developed by the center for disease dynamics economics and policy (CDDEP) for India, these bacteria shows average resistance of 50 to $80 \%$ to penicillin's like ampicillin, amoxicillin, third-generation cephalosporin's and fluoroquinolone and even to combinations antibiotics such as amoxicillin-clavulanic acid.

The prior studies on bacterial resistance indicates that Gram negative bacteria like Acinetobacter baumannii, Escherichia coli, Klebsiella pneumonia and Pseudomonas aeruginosa develops resistance by limiting uptake of antibiotics in to the cell, inactivation or modification of antibiotics and efflux pump activation. In contrast, Gram positive bacteria like Enterococcus faecium, Enterococcus faecalis and Staphylococcus aureus develops resistance by inactivation or modification of the antibiotics and less likely through activation of efflux pump and limiting uptake of antibiotics. ${ }^{3-5}$

Prior studies on resistance mechanism of bacteria also depicts that majority of the MDR bacteria reduces the efficacy of the antibiotic through efflux pump activation or over-expression. Typically by extruding the antibiotic out of the bacterial cell, thereby reducing the concentration of antibiotics at the site of action required for relevant antibacterial activity. ${ }^{6,7}$

In the year 2010, with the successful launch of Resorine by Cadila Pharmaceutical as anti-tuberculosis drug comprising combination of antibiotics (Rifampicin$200 \mathrm{mg}$, Isoniazid-300mg) and efflux pump inhibitor (Piperine-10mg), ${ }^{8,9}$ has created boost in the scientific world to analyze potential of various phyto-constituents of medicinal plants. Scientist from the various parts of the globe started evaluating the efflux pump inhibiting potential of isolated phyto-constituents mainly phenolic, flavonoids and alkaloids such as piperine, curcumin, reserpine, gingerol, shagol, quercetin, rutin and the like. In addition, scientist used computational tools such as in-silico molecular docking to identify the efflux pump inhibiting potential of the various phyto-constituents. But even after 10 years from Resorine discovery, no new combination of antibiotic and efflux pump inhibitor has been launched mainly due to complexity of the phyto-constituent structures, its yield after isolation, lack of robustness in the in-vitro and in-vivo methods. In addition, the prior art is focused only on isolated phyto-constituents and not on the use of combination of phyto-constitutes present in the whole plant.

Accordingly, the present paper is focused on comparative analysis of black pepper phyto-constitutes as E. coli efflux pump inhibitors using in-silico molecular docking.

\section{MATERIALS AND METHODS}

In the present paper, the in-silico molecular docking was used as a tool to predict the binding affinity between the phyto-constitutes of the black pepper fruits (Ligand) and the efflux pump of the E. coli (Protein) was analyzed.

\section{Ligand Selection}

The literature work published in the SOCPUS, Web of Science and PubMed, more than $30 \%$ of research papers are exploring either usage of piperine as an efflux pump inhibitor for gram negative bacteria such as Pseudomonas aeruginosa and E. coli or possible use of black pepper fruit extract and piperine as an antibacterial. In addition, the phyto-constitutes explored in the literatureas theefflux pumpinhibitorcompriseseither two co-planner aromatic ring or positively charged nitrogen or carbonyl group separated by hydrophilic and lipophilic moiety. ${ }^{10,11}$

Accordingly, the alkaloids and the phenolic compound present in the fruit of the black pepper such as piperine, beta-thujene, pinene, limonene, beta- caryophyllene, linalool, beta-selinene were selected as Ligands for the in-silico molecular docking. ${ }^{12,13}$ The chemical structures and the hydrophilic and lipophilic moiety present in the ligand phyto-constituents are shown in Table 1.

\section{Selection of antibiotic}

With reference to the Resistance map developed by CDDEP, $80 \%$ to $90 \%$ is the resistance rate of E. coli to aminopenicillin such as ampicillin and amoxicillin, as well as to the combination of amoxicillin and clavulanic acid. Accordingly, amoxicillin is selected as a ligand for EmrD.

\section{Efflux Pump of the E-coli (Protein)}

E. coli, comprise 3 efflux pump families namely, the major facilitator superfamily (MFS), the resistance nodulation-cell division (RND) family and the small 


\begin{tabular}{|c|c|c|c|}
\hline $\begin{array}{c}\text { Ligand } \\
\text { (PubChem CID) }\end{array}$ & Molecular Structures & $\begin{array}{l}\text { Molecular } \\
\text { Formula }\end{array}$ & $\begin{array}{l}\text { Molecular } \\
\text { weight }\end{array}$ \\
\hline $\begin{array}{l}\text { Piperine } \\
638024\end{array}$ & & $\mathrm{C}_{17} \mathrm{H}_{19} \mathrm{NO}_{3}$ & $285.34 \mathrm{~g} / \mathrm{mol}$ \\
\hline $\begin{array}{l}\text { Limonene } \\
22311\end{array}$ & & $\mathrm{C}_{10} \mathrm{H}_{16}$ & $136.23 \mathrm{~g} / \mathrm{mol}$ \\
\hline $\begin{array}{c}\beta \text {-Thujene } \\
520384\end{array}$ & & $\mathrm{C}_{10} \mathrm{H}_{16}$ & $136.23 \mathrm{~g} / \mathrm{mol}$ \\
\hline $\begin{array}{c}\beta \text {-Caryophyllene } \\
5281515\end{array}$ & & $\mathrm{C}_{15} \mathrm{H}_{2}$ & $204.35 \mathrm{~g} / \mathrm{mol}$ \\
\hline $\begin{array}{c}\text { Linalool } \\
6549\end{array}$ & & $\mathrm{C}_{10} \mathrm{H}_{18} \mathrm{O}$ & $154.25 \mathrm{~g} / \mathrm{mol}$ \\
\hline $\begin{array}{c}\beta \text {-Selinene } \\
348290135\end{array}$ & & $\mathrm{C}_{15} \mathrm{H}_{24}$ & $204.35 \mathrm{~g} / \mathrm{mol}$ \\
\hline $\begin{array}{l}\text { Pinene } \\
440967\end{array}$ & & $\mathrm{C}_{10} \mathrm{H}_{16}$ & $136.23 \mathrm{~g} / \mathrm{mol}$ \\
\hline $\begin{array}{c}\text { Amoxicillin } \\
62883\end{array}$ & & $\mathrm{C}_{16} \mathrm{H}_{19} \mathrm{~N}_{3} \mathrm{O}_{5} \mathrm{~S}$ & $365.4 \mathrm{~g} / \mathrm{mol}$ \\
\hline
\end{tabular}

multidrug resistance (SMR). Each family comprise of different transporters such as MFS incudes EmrD, mdfA, emrB, RND has acrB, acrF and SMR has emrE $(\mathrm{mvrC})$ and tehA. ${ }^{14}$

Amongst these transporters EmrD is capable to export a broad spectrum of antibiotic molecules from the cell wall of E. coli. Therefore, EmrD of E. coli with 394 amino acids, 12 transmembrane $\alpha$-helices and a molecular weight of $42.2 \mathrm{kD}$ is selected for the molecular docking studies.

\section{Preparation Ligands and Protein for Docking}

The structure of Ligands with their respective PubChem CID as depicted in Table 1 were saved in SDF format. These structure were converted to PDB format using Pymol software. The 3D structure of EmrD was retrieved using RCSB (http://www.rcsb.org/pdb/) structure file (PDB ID: 2GFP)

AutoDock 4.2.6 program was used to obtain the docking of EmrD of E. coli with the ligands. The implemented empirical free energy function and the Lamarckian Genetic Algorithm (LGA) and the grid maps as depicted in Table 2 was used to obtain binding energy, $\mathrm{H}$. bonds, interacting residues, intermolecular energy and Torsion free energy.

The interactions of complex EmrD and ligand conformations comprising hydrogen bonds and bond lengths were analyzed using Pymol software, UCSF Chimera, Molegro Molecular Viewer and Accelrys DS Visualizer software. Discovery studio 2020 Client and Chimera softwares were also used to depict Hydrogen bonds, 2-D images and protein-ligand interactions images for a visualization of the docking. The best conformation with the lowest docked energy was chosen from the docking search. Number of torsions are chosen from 0-6 and any ligand showed more than 6 was adjusted to 6 .

\section{Drug-like properties of the Ligands}

Lipinski's filters were used to determine Absorption, Distribution, Metabolism, Excretion and Toxicity (ADMET) and Drug-like properties of the Ligand Phyto-compounds Piperine, B- thujene, $\alpha$ - and $\beta$-pinene, myrcene, $\alpha$-phellandrene, limonene, B caryophyllene, linalool and B-selinene. 
Table 2: Molecular Docking Grid data for EmrD.

\begin{tabular}{|c|c|c|}
\hline Sr. No. & Grid Data & Details \\
\hline 1 & PDBID & 2 GFP \\
\hline 2 & Resolution: & $3.50 \AA$ \\
\hline 3 & Sequence Length & 375 \\
\hline 4 & Grid Point Spacing & 1.00 Angstroms \\
\hline 5 & $\begin{array}{c}\text { Even Number of User- } \\
\text { specified Grid Points }\end{array}$ & $\begin{array}{c}50 \text { x-points, } 50 \\
\text {-points, 50 z-points }\end{array}$ \\
\hline 6 & $\begin{array}{c}\text { Coordinates of Central Grid } \\
\text { Point of Maps }\end{array}$ & $\begin{array}{c}(-4.221,-15.995, \\
27.731)\end{array}$ \\
\hline 7 & Minimum coordinates in grid & $(-29.221,-40.995$, \\
& & $2.731)$ \\
\hline 8 & Maximum coordinates in grid & $(20.779,9.005,52.731)$ \\
\hline
\end{tabular}

\section{RESULTS}

The docking interactions between ligand phytocompounds, amoxicillin and targeted E-coli EmrD MDR protein are shown in Table 3 and Table 4. It was found that phyto-compound ligands piperine $(-6.23 \mathrm{kcal} / \mathrm{mol})$, beta caryophyllene $(-6.36 \mathrm{kcal} / \mathrm{mol})$, beta selinene $(-6.93 \mathrm{kcal} / \mathrm{mol})$, beta-Thujene $(-5.42 \mathrm{kcal} / \mathrm{mol})$ requires less binding energy for the $\mathrm{EmrD}$ as compared to Amoxicillin $(-5.85 \mathrm{kcal} / \mathrm{mol})$. This indicates that the phyto-compounds will bind easily with E. coli EmrD as compared to amoxicillin. Consequently, reducing the expulsion of amoxicillin out of the bacterial cell and thereby maintaining the therapeutic concentration of amoxicillin at the site of action required for expected antibacterial activity. ${ }^{15,16}$

The Torsional free energy of the phyto-constitutes typically, piperine $(+0.89)$, beta caryophyllene $(+0.00 \mathrm{kcal} / \mathrm{mol})$, beta selinene $(+0.30)$, beta-Thujene $(+0.30 \mathrm{kcal} / \mathrm{mol})$ in comparison with amoxicillin $(+2.93 \mathrm{kcal} / \mathrm{mol})$ further provides evidence for strong binding affinity with EmrD and phyto-constituents as compared to amoxicillin.

Though phyto constituents such as Limonene (-5.49 $\mathrm{kcal} / \mathrm{mol})$, Pinene $(-5.69 \mathrm{kcal} / \mathrm{mol})$ showed less binding energy than Amoxicillin $(-5.85 \mathrm{kcal} / \mathrm{mol})$, but, the Torsional free energy for these phyto-constituents is $+0.00 \mathrm{kcal} / \mathrm{mol}$ as compared to amoxicillin $+2.93 \mathrm{kcal} / \mathrm{mol}$ providing further support for use of combination of phyto-constituents of black pepper with amoxicillin in the management of MDR E. coli.

The ADMET properties of the ligands showed that optimum human intestinal solubility (HIA), blood brain barrier (BBB) penetration with no carcinogenicity.

\section{Ligand Protein Interactions}

Lipinski's Rule: Drug-like properties of the Phytocompounds

Lipinski's rule was used to analyze the drug likeness attributes such as human intestinal absorptivity, permeation through Blood Brain Barrier (BBB), Carcinogenicity and Toxicity-Lethal Dose $\left(\mathrm{LD}_{50}\right)$

The Lipinski Rule depicts the suitability of the drug molecules for oral administered. The Rule is based on the parameters such as hydrogen acceptors less than 10 and hydrogen donors less 5, molecular weight should be more than 500 daltons and partition coefficient $(\log \mathrm{P})$ should not be less than 5 . The Ligand Properties as per Lipinski's rule and ADMET are shown in Table 5 and 6 respectively.

Absorption, Distribution, Metabolism, Excretion and Toxicity (ADMET) properties, as derived from AdmetSAR reveal that the ligands have optimum Human Intestinal Absorption (HIA) score and significantly low carcinogenicity and $\mathrm{BBB}$ penetration potential directing towards safe use of combination of amoxicillin and whole black pepper extract in the managementofMDR E. coli. ${ }^{17-19}$ The $\mathrm{LD}_{50}$ doses of all the ligands indicates that Piperine, $(2.7129 \mathrm{~mol} / \mathrm{kg}$ ) and Amoxicillin (1.7036) has greater oral toxicity compared to the other ligands.

\section{DISCUSSION}

The emergence of MDR bacteria typically, gram negative bacteriahasmushroomed with discoveryand development of every new class of antibiotics. In the year 2019, WHO had directed about emergence of antibiotic pandemic due to steady increase in morbidity and mortality due to MDR bacterial infections. ${ }^{1,20}$ WHO report is also imperative to indicate that the speed at which the bacteria are showing the resistance to available antibiotics is not matching with the discovery of new antibacterial which might lead to no-antibiotic era. In order to resolve the problem of limitation to develop a new broad spectrum antibiotics, combinations of two or more antibiotics with different mechanism of action or use of antibiotic adjuvant like beta lactamase was preferred in the management of MDR infections. Though the combination therapy provides a broader antimicrobial spectrum, synergistic effects but it is equally contributing to the reoccurrence of MDR infections. ${ }^{21,22}$

Moreover, study of Intrinsic and extrinsic mechanism developed by bacteria indicates that overexpressed efflux pumps is one of the main survival weapon. It is apparent that the identification of antibiotic adjuvant having capability to inhibit the efflux protein without imparting any additional antibacterial activity is required. ${ }^{23-27}$

The results of interaction between EmrD and Phytocompound ligands clearly depicts combination of black pepper phyto-constituents has synergistic effect 


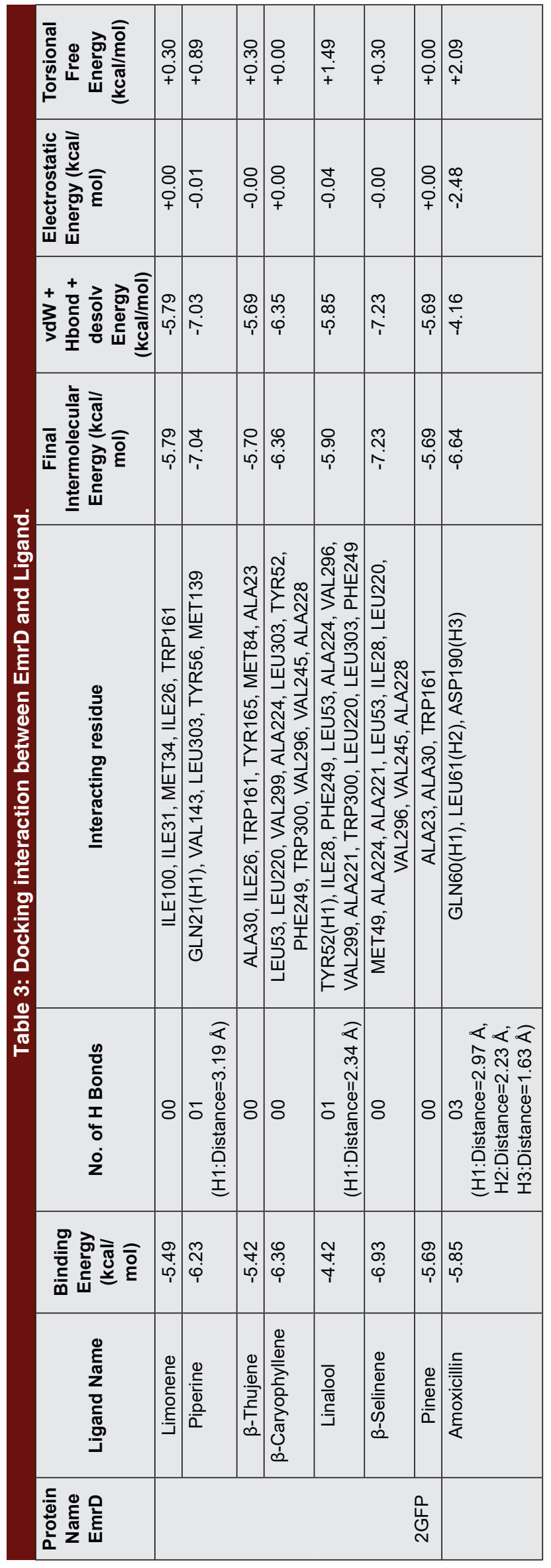

as compared to isolated piperine. Further, the ADMET analysis shows that these phyto-compounds of black pepper are safe for oral administration especially with reference to human Intestinal absorptivity, possibility of crossing $\mathrm{BBB}$ and toxicity $\left(\mathrm{LD}_{50}\right)$.

\section{CONCLUSION}

The present study of in-silico molecular docking provides evidence that phyto-compounds of black pepper binds to efflux pump EmrD of E. coli responsible for reducing the antibacterial potential of amoxicillin. ${ }^{28-30}$ Further, present study provide additional properties such as druglikeness, ADMET prediction and toxicity analysis, which could help in developing non-toxic and effective combination formulation of phyto-compounds and amoxicillin. ${ }^{31,32}$

Accordingly, in the present paper in silico molecular docking approaches is used to provide reliable predictions as well as new knowledge on the Emrd inhibition potential of phyto-constituents of black pepper and using these phyto-constituents as adjuvants ${ }^{33,34}$ for amoxicillin.

\section{ACKNOWLEDGEMENT}

The authors are grateful to Dr. Vaibhav Sable for providing support to use Docking software.

\section{CONFLICT OF INTERST}

The authors declare no conflict of interest

\section{ABBREVIATIONS}

MDR: Multi Drug Resistance; RND: Resistance nodulation-cell division; MFS: Major facilitator superfamily; ADMET: Absorption, Distribution, Metabolism, Excretion and Toxicity; LGA: Lamarckian Genetic Algorithm.

\section{REFERENCES}

1. Prioritization of pathogens to guide discovery, research and development of new antibiotics for drug resistant bacterial infections, including tuberculosis [internet]. World Health Organization; 2021 [cited Mar 1 2021]. Available from: https://www.who.int/medicines/areas/rational_use/prioritization-of-pathogens/ en/.

2. Tiseo K, Huber L, Gilbert M, Robinson TP, Van Boeckel TP. Global trends in antimicrobial use in food animals from 2017 to 2030. Antibiotics (Basel). 2020;9(12):918. doi: 10.3390/antibiotics9120918, PMID 33348801

3. Seukep AJ, Kuete V, Nahar L, Sarker SD, Guo M. Plant-derived secondary metabolites as the main source of efflux pump inhibitors and methods for identification. J Pharm Anal. 2020;10(4):277-90. doi: 10.1016/j. jpha.2019.11.002, PMID 32923005.

4. Sulavik MC, Houseweart C, Cramer C, Jiwani N, Murgolo N, Greene J, DiDomenico B, Shaw KJ, Miller GH, Hare R, Shimer G. Antibiotic 


\section{Table 4: Multidrug resistance associate protein (PDB ID: 2GFP) docking with Legand.}

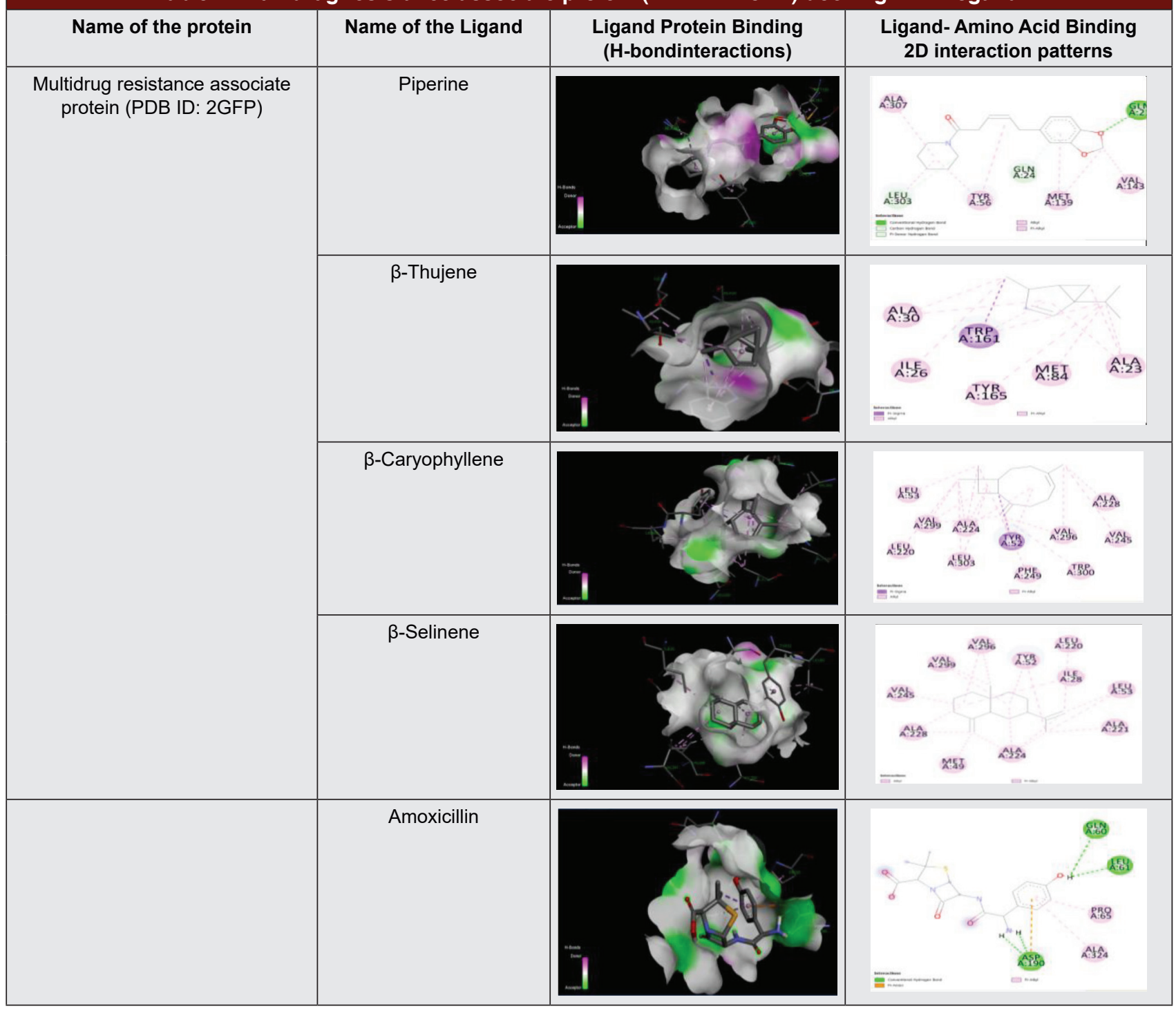

\begin{tabular}{|c|c|c|c|c|c|c|}
\hline Sr. No. & Ligand Name & $\begin{array}{l}\text { Molecular Weight in } \mathrm{g} / \mathrm{mol} \\
\qquad(<500)\end{array}$ & $\begin{array}{c}\log P \\
(\leq 5)\end{array}$ & $\begin{array}{l}\text { Hydrogen Bond } \\
\text { Donor } \\
(\leq 5)\end{array}$ & $\begin{array}{l}\text { Hydrogen Bond } \\
\text { Acceptor }(\leq 10)\end{array}$ & $\begin{array}{l}\text { Rotatable } \\
\text { Bond Count }\end{array}$ \\
\hline 1 & Piperine & $285.34 \mathrm{~g} / \mathrm{mol}$ & 3.5 & 0 & 3 & 3 \\
\hline 2 & limonene & $136.23 \mathrm{~g} / \mathrm{mol}$ & 3.4 & 0 & 0 & 1 \\
\hline 3 & $\beta$-Thujene & $136.23 \mathrm{~g} / \mathrm{mol}$ & 3.4 & 0 & 0 & 1 \\
\hline 4 & $\beta$-Caryophyllene & $204.35 \mathrm{~g} / \mathrm{mol}$ & 4.4 & 0 & 0 & 0 \\
\hline 5 & Linalool & $154.25 \mathrm{~g} / \mathrm{mol}$ & 2.7 & 1 & 1 & 4 \\
\hline 6 & $\beta$-selinene & $204.35 \mathrm{~g} / \mathrm{mol}$ & 5.4 & 0 & 0 & 1 \\
\hline 7 & Amoxicillin & $365.4 \mathrm{~g} / \mathrm{mol}$ & -2 & 4 & 7 & 4 \\
\hline 8 & Pinene & $136.23 \mathrm{~g} / \mathrm{mol}$ & 3.1 & 0 & 0 & 0 \\
\hline
\end{tabular}




\begin{tabular}{|c|c|c|c|c|c|}
\hline \multicolumn{7}{|c|}{ Table 6: ADMET properties of the Ligands. } \\
\hline SN & Compound & HIA & BBB & Carcinogenicity & LD $_{50}$ in Rat (mol/kg) \\
\hline 1 & Piperine & 0.9964 & 1.0000 & Non-carcinogens & 2.7129 \\
\hline 2 & Limonene & 0.9444 & 0.9887 & Non-carcinogens & 1.4819 \\
\hline 3 & B-thujene & 0.9804 & 0.9973 & Non-carcinogens & 1.6406 \\
\hline 4 & B-caryophyllen & 0.9564 & 0.9923 & Non-carcinogens & 1.4345 \\
\hline 5 & B-selinene & 0.9732 & 0.9947 & Non-carcinogens & 1.4979 \\
\hline 6 & Pinene & 0.9628 & 0.9942 & Non-carcinogens & 1.4350 \\
\hline 7 & Amoxicillin & 0.9967 & 0.9008 & Non-carcinogens & 1.7036 \\
\hline
\end{tabular}

susceptibility profiles of Escherichia coli Strains lacking multidrug efflux pump genes. Antimicrob Agents Chemother. 2001;45(4):1126-36. doi: 10.1128/ AAC.45.4.1126-1136.2001, PMID 11257026.

5. Pallah O, Meleshko T, Tymoshchuk S, Yusko L, Bugyna L. How to escape 'the eskape pathogens' using plant extracts. ScienceRise. J Biol Sci. 2020;0(56(20-21):30-7

6. Masi M, Réfregiers M, Pos KM, Pagès JM. Mechanisms of envelope permeability and antibiotic influx and efflux in Gram-negative bacteria. Nat Microbiol. 2017;2(3):17001. doi: 10.1038/nmicrobiol.2017.1, PMID 28224989.

7. Spengler G, Kincses A, Gajdács M, Amaral L. New Roads leading to old destinations: efflux pumps as targets to reverse multidrug resistance in bacteria. Molecules. 2017;22(3):468. doi: 10.3390/molecules22030468, PMID 28294992.

8. Murase LS, Perez de Souza JV, Meneguello JE, Seixas FAV, Hegeto LA, Scodro RBdL, Siqueira VLD, Caleffi Ferracioli KR, Cardoso RF. Possible Binding of piperine inMycobacterium tuberculosisRNA polymerase and rifampin Synergism. Antimicrob Agents Chemother. 2019;63(11). doi: 10.1128/AAC.02520-18.

9. Patel N, Jagannath K, Vora A, Patel M, Patel A. A randomized, controlled, phase iii clinical trial to evaluate the efficacy and tolerability of risorine with conventional rifampicin in the treatment of newly diagnosed pulmonary tuberculosis patients. J Assoc Physicians India. 2017;65(9):48-54. PMID 29313577.

10. Joshi P, Singh S, Wani A, Sharma S, Jain S, Singh B, et al. Osthol and curcumin as inhibitors of human Pgp and multidrug efflux pumps of Staphylococcus aureus: reversing the resistance against frontline antibacterial drugs. Med. Chem Commun. 2014;5(10):1540-7.

11. Screening method for the identification of bioenhancers through the inhibition of P-glycoprotein transport in the gut of a mammal. US; 5567592, 1994.

12. PLOS ONE Staff. Correction: molecular modelling and simulation studies of the Mycobacterium tuberculosis multidrug efflux pump protein Rv1258c. PLOS ONE. 2018;13(12):e0209717. doi: 10.1371/journal.pone.0209717, PMID 30566521.

13. Sharma S, Kumar M, Sharma S, Nargotra A, Koul S, Khan IA. Piperine as an inhibitor of Rv1258c, a putative multidrug efflux pump of Mycobacterium tuberculosis. J Antimicrob Chemother. 2010;65(8):1694-701. doi: 10.1093/ jac/dkq186, PMID 20525733.

14. Lam AK, Panlilio H, Pusavat J, Wouters CL, Moen EL, Rice CV. Overcoming multidrug resistance and biofilms of Pseudomonas aeruginosa with a Single dual-Function Potentiator of $\beta$-lactams. ACS Infect Dis. 2020;6(5):1085-97. doi: 10.1021/acsinfecdis.9b00486, PMID 32223216.

15. Douafer $\mathrm{H}$, Andrieu V, Phanstiel O, Brunel JM. Correction to antibiotic adjuvants: make antibiotics great again! J Med Chem. 2020;63(3):1440-. doi: 10.1021/acs.jmedchem.9b02109, PMID 31961155.

16. Maurya N, Jangra M, Tambat R, Nandanwar H. Alliance of Efflux Pumps with $\beta$-lactamases in multidrug-ResistantKlebsiella pneumoniaelsolates. Microb Drug Resist. 2019;25(8):1155-63. doi: 10.1089/mdr.2018.0414, PMID 31613200.

17. Allen RC, Brown SP. Modified antibiotic adjuvant ratios can slow and steer the evolution of resistance: Co-amoxiclav as a case study. mBio. 2019;10(5). doi: 10.1128/mBio.01831-19, PMID 31530673.
18. Laws M, Shaaban A, Rahman KM. Antibiotic resistance breakers: current approaches and future directions. FEMS Microbiol Rev. 2019;43(5):490-516. doi: 10.1093/femsre/fuz014, PMID 31150547.

19. Sharma A, Gupta VK, Pathania R. Efflux pump inhibitors for bacterial pathogens: from bench to bedside. Indian J Med Res. 2019;149(2):129-45. doi: 10.4103/ijmr.IJMR_2079_17, PMID 31219077.

20. Luan W, Liu X, Wang X, An Y, Wang Y, Wang C, Shen K, Xu H, Li S, Liu M, Yu LU. Inhibition of Drug Resistance of Staphylococcus aureus by Efflux Pump Inhibitor and Autolysis Inducer to Strengthen the antibacterial activity of $\beta$-lactam Drugs. Pol J Microbiol. 2019;68(4):477-91. doi: 10.33073/pjm2019-047, PMID 31880892.

21. Ogawara H. Comparison of antibiotic resistance mechanisms in antibioticproducing and pathogenic bacteria. Molecules. 2019;24(19):3430. doi: 10.3390/molecules24193430, PMID 31546630.

22. Peterson E, Kaur P. Antibiotic Resistance Mechanisms in Bacteria: Relationships Between Resistance Determinants of Antibiotic Producers, Environmental Bacteria, and Clinical Pathogens. Front Microbiol. 2018;9:2928. doi: 10.3389/fmicb.2018.02928, PMID 30555448.

23. \&na;. Current opinion in infectious diseases. Curr Opin Infect Dis. 1998;11(5):601. doi: 10.1097/00001432-199810000-00013.

24. Webber MA, Piddock LJ. The importance of efflux pumps in bacterial antibiotic resistance. J Antimicrob Chemother. 2003;51(1):9-11. doi: 10.1093/ jac/dkg050, PMID 12493781

25. Cox G, Wright GD. Intrinsic antibiotic resistance: mechanisms, origins, challenges and solutions. Int J Med Microbiol. 2013;303(6-7):287-92. doi: 10.1016/j.jimm.2013.02.009, PMID 23499305.

26. Walsh C. Molecular mechanisms that confer antibacterial drug resistance. Nature. 2000;406(6797):775-81. doi: 10.1038/35021219, PMID 10963607.

27. Machado Fonseca F. A present and global threat called ExtendedSpectrum Beta-lactamases (ESBLs). Current Trends on Biotechnology and microbiology: open Access Publishers. Vol. 1(1); 2018.

28. Malhotra R. Extended spectrum beta lactamases-important resistance threat Int J Sci Res. 2012;2(11):448-50. doi: 10.15373/22778179/NOV2013/148.

29. Shah AA, Hasan F, Ahmed S, Hameed A. Extended-Spectrum $\beta$-lactamases (ESBLs): characterization, Epidemiology and Detection. Crit Rev Microbiol. 2004;30(1):25-32. doi: 10.1080/10408410490266429, PMID 15116761.

30. Giedraitienè A, Vitkauskienè A, Naginienè R, Pavilonis A. Antibiotic resistance mechanisms of clinically important bacteria. Medicina (Kaunas). 2011;47(3):137-46. doi: 10.3390/medicina47030019, PMID 21822035.

31. González-Bello C. Antibiotic adjuvants - A strategy to unlock bacterial resistance to antibiotics. Bioorg Med Chem Lett. 2017;27(18):4221-8. doi: 10.1016/j.bmcl.2017.08.027, PMID 28827113.

32. Sharma N, Chhillar AK, Dahiya S, Choudhary P, Punia A, Gulia P. Antibiotic adjuvants: a promising approach to combat multidrug resistant bacteria. Curr Drug Targets. 2021;22. doi: 10.2174/1389450122666210120084406, PMID 33494671.

33. D'Andrea MM, Fraziano M, Thaller MC, Rossolini GM. The urgent need for novel antimicrobial agents and strategies to fight antibiotic resistance. Antibiotics (Basel). 2019;8(4):254. doi: 10.3390/antibiotics8040254, PMID 31817707.

34. Tegos GP, Haynes M, Strouse JJ, Khan MM, Bologa CG, Oprea TI, Sklar LA. Bologa C, I. Oprea T et al. Microbial efflux pump inhibition: tactics and strategies. Curr Pharm Des. 2011;17(13):1291-302. doi: 10.2174/138161211795703726, PMID 21470111. 
PICTORIAL ABSTRACT

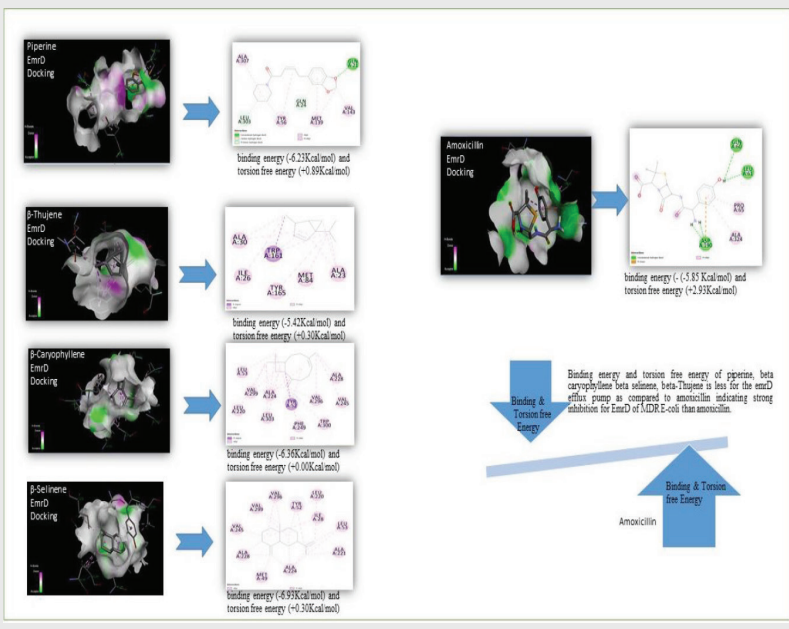

\section{SUMMARY}

The present paper is aimed to evaluate the potential of various phenolic phyto-compounds of black pepper as the amoxicillin adjuvants in comparison with isolated piperine against the MDR E. coli. using in-silico molecular docking. The result indicates that binding energy $(\mathrm{Kcal} / \mathrm{mol})$ and torsion free energy $(\mathrm{Kcal} / \mathrm{mol})$ of piperine $(-6.23,+0.89)$, beta caryophyllene $(-6.36,+0.00)$, beta selinene $(-6.93,+0.30)$, beta-Thujene $(-5.42$, +0.30 ) is less for the emrD efflux pump as compared to amoxicillin $(-5.85,+2.93)$ respectively indicating strong inhibition for EmrD of MDR E. coli than amoxicillin. The results are also indicating that black pepper extract containing all aforementioned phytoconstituents has synergistic effect in comparison with isolated piperine against the MDR E. coli.

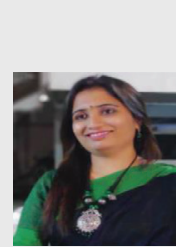

\section{About Authors}

Mrs. Prerana Dongre, Symbiosis Institute of Health Sciences, Symbiosis International (Deemed University), Pune, India

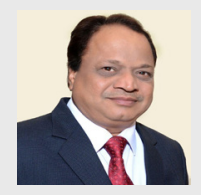

Dr. Rajendra S Bhambar, Principal, MGV's Panchavati College of Pharmacy. Nasik, Maharashtra, India.

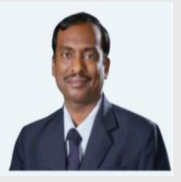

Dr. Satish A Polshettiwar School of Pharmacy, Dr. Vishwanath Karad, MIT World Peace University, Pune 411038, Maharashtra, India

Cite this article: Dongre P, Bhambar RS, Polshettiwar SA. In silico and Molecular Docking Studies of Black Pepper Phyto-constituents against EmrD Efflux Pump of E. coli. Indian J of Pharmaceutical Education and Research. 2022;56(1):199-206. 